\title{
Standardization of genetic tests needed
}

Published at www.cmaj.ca on Sept. 14

$\mathrm{E}$ volving knowledge of the genetic indicators of disease is rapidly changing medical care, and overwhelming the ability of regulatory agencies to ensure the quality and accuracy of such tests.

"We're doing [genetic testing] for lung cancer, for colon cancer, for breast cancer, for melanoma, myeloma," says Dr. Suzanne Kamel-Reid, head of laboratory genetics and director of molecular diagnostics at the University Health Network in Toronto, Ontario, and head of the Molecular Oncology Task Force which is sponsored by Cancer Care Ontario. "It's used much, much more frequently than it used to be." According to the task force, referrals for cancer-related genetic testing rose $61 \%$ in 22 clinics surveyed between 2002 and 2008 .

The increased use is also evident in the United States, so much so that the US Food and Drug Administration (FDA) says about $10 \%$ of pharmaceuticals are now labelled as being especially useful — or not so useful — for patients with specific genetic conditions.

But a lack of standardization in Ontario means that genetic testing is done on an ad hoc basis. Labs with resources develop "home brew" tests that are not necessarily available at other sites.

"We need to have a test menu that's available to all patients in Ontario no matter where they live," Kamel-Reid says. "Right now there isn't a standardized menu of tests and doctors often do not know that a test that can help their patient is available."

Moreover, doctors occasionally turn to research labs for genetic tests, unaware that those tests are unlicensed for clinical tests. Research labs do not need to declare the tests they perform on their laboratory license, are not inspected by the Ontario Laboratory Accreditation and do not undergo proficiency testing.

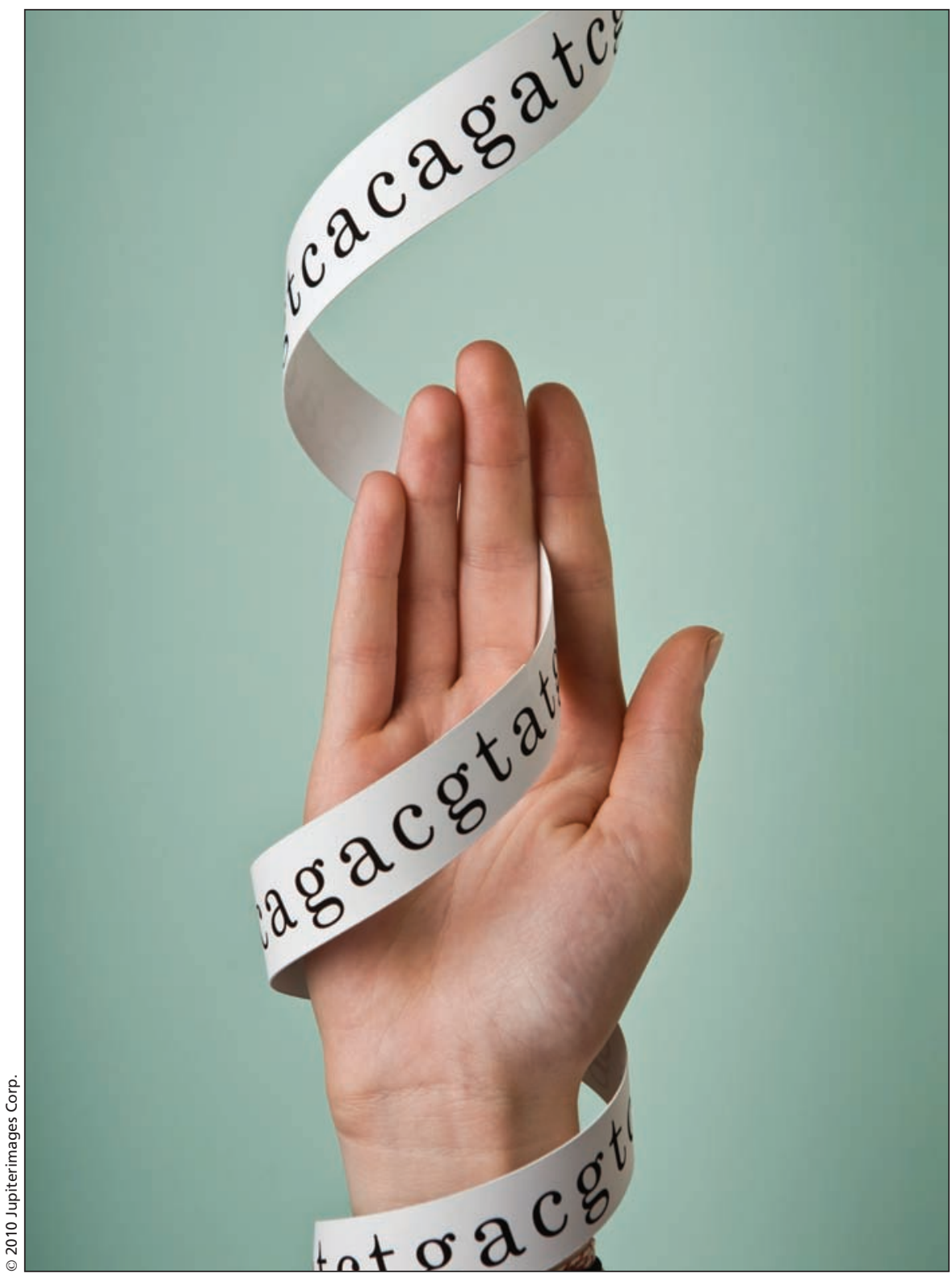

The United States Food and Drug Administration is currently examining means of standardizing direct-to-consumer tests.

That all but invites error, says Kamel-Reid.

The same is true of the global explosion in private companies offering genetic testing services that claim to predict clients predispositions to a range of diseases from Alzheimer to diabetes. Typically, such companies charge a brisk US $\$ 300$ to US $\$ 1000$.
That was apparent in the findings of a US Government Accountability Office investigation in which the DNA samples of five volunteers were sent to four different "direct-to-consumer" genetic testing companies. Completely contradictory results emerged. For example, three companies informed one donor that he alternatively had a 
low, average and a high risk of developing prostate cancer (www.gao.gov /new.items/d10847t.pdf).

In its report, Direct-to-Consumer Genetic Tests, the watchdog agency expressed concern that tests determining disease predictability were "more of an art than a science" and warned that inaccurate risk predictions can have serious implications For example, a woman who is told she is at high risk of developing ovarian cancer may have her ovaries removed. The report also noted that such firms aren't obliged to follow clinical standards with regard to counselling and consent, which could lead to unanticipated and severe anxiety.

The FDA is currently examining means of standardizing direct-toconsumer tests, says Elizabeth Mansfield, director for personalized medicine in the agency's office of in vitro diagnostics. The FDA decided in the 1970s that it would not enforce approval requirements on lab-developed tests because they were largely developed by hospital-based labs to process small volumes of samples and were generally overseen by pathologists and clinicians.

But tests can now "be marketed from a single laboratory and sold across the country," Mansfield says.

Predictably, the industry is opposed to standardization.

The FDA shouldn't stop companies from interpreting genetic data, says Jorge Conde, CEO of Massachusetts-based Knome, which maps a client's entire genome for tens of thousands of dollars. "I don't think it's practical to assume that we can stop people from accessing their own information. Everyone can get access to their own DNA because it is coursing through their veins."

Rather, the government should merely regulate how information is marketed and communicated, Conde says. "There should be a clear disclaimer what exactly what this information can tell you and, more importantly, what it cannot tell you."
Variations found by the Government Accountability Office study may have occurred because firms use different algorithms to determine risk, Conde says, adding that at Knome, geneticists discuss the studies with clients rather than assigning a risk percentage.

One of the firms in the study, 23andMe, states in an email that while it is adamant that the government shouldn't stop people from accessing information about their DNA, it encourages customers to "discuss their data" with a health professional.

That's the problem, says KamelReid. Canadian patients who send their data to a US firm end up in Canadian health clinics. "Patients come and say I've been tested and I'm going to develop Alzheimer's when I'm 50, what can I do about this?" she says. "It does impact our health system." Wendy Glauser, Toronto, Ont.

DOI:10.1503/cmaj.109-3669 